\title{
A Mediterranean and a high-carbohydrate diet improve glucose metabolism in healthy young persons
}

\author{
F.Pérez-Jiménez ${ }^{1}$, J. López-Miranda ${ }^{1}$, M.D.Pinillos ${ }^{1}$, P. Gómez ${ }^{1}$, E.Paz-Rojas ${ }^{1}$, P.Montilla ${ }^{1}$, C. Marín ${ }^{1}$, \\ M.J. Velasco ${ }^{1}$, A. Blanco-Molina ${ }^{1}$, J. A. Jiménez Perepérez ${ }^{1}$, J. M. Ordovás ${ }^{2}$ \\ ${ }^{1}$ Lipid and Arteriosclerosis Research Unit and the Biochemistry Laboratory, Reina Sofia University Hospital and Medical School, \\ University of Cordoba, Spain \\ ${ }^{2}$ Lipid Metabolism Laboratory, U.S. Department of Agriculture, Human Nutrition Research Center on Aging, Tufts University, \\ Boston, Mass., USA
}

\section{Abstract}

Aims/hypothesis. Insulin resistance usually precedes the diagnosis of Type II (non-insulin-dependent) diabetes mellitus. However, in most patients, the clinical expression of the disease could be prevented by dietary and lifestyle changes. We investigated the effects of a diet enriched in monounsaturated fatty acids (Mediterranean diet) and a low fat, high-carbohydrate diet on in vivo and in vitro glucose metabolism in 59 young subjects ( 30 men and 29 women).

Methods. We carried out an intervention dietary study with a saturated fat phase and two randomized-crossover dietary periods: a high-carbohydrate diet and a Mediterranean diet for 28 days each. We analysed the plasma lipoproteins fractions, free fatty acids, insulin sensitivity and glucose uptake in isolated monocytes at the end of the three dietary periods. Results. In comparison to the saturated fat diet, the $\mathrm{CHO}$ and Mediterranean diets induced a decrease of LDL-cholesterol $(p<0.001)$ and HDL-cholesterol $(p<0.001)$. Steady-state plasma glucose decreased $(p=0.023)$ and basal and insulin-stimulated 2-deoxiglucose uptake in peripheral monocytes increased in both diets (CHO and Mediterranean), $(p=0.007)$ indicating an improvement in insulin sensitivity. Fasting free fatty acids plasma values were correlated positively with steady state plasma glucose $(r=0.45$; $p<0.0001)$. In addition, there was an inverse correlation between the mean glucose of the steady state plasma glucose period and logarithmic values of basal $(r=-0.34 ; p=0.003)$ and insulin stimulated glucose uptake in monocytes $(r=-0.32 ; p=0.006)$.

Conclusion/interpretation. Isocaloric substitution of carbohydrates and monounsaturated fatty acids for saturated fatty acids improved insulin sensitivity in vivo and in vitro, with an increase in glucose disposal. Both diets are an adequate alternatives for improving glucose metabolism in healthy young men and women. [Diabetologia (2001) 44: 2038-2043]

Keywords Mediterranean diet, $\mathrm{CHO}$-diet, insulin sensitivity, glucose metabolism, monounsaturated fat, monocytes.
Insulin resistance, or the relative inability of insulin to facilitate the disposal of glucose in tissues, is considered to be a risk factor for both diabetes and coro-

Received: 19 February 2001 and in revised form: 9 July 2001

Corresponding author: F. Pérez-Jiménez, Facultad de Medicina. Avda Menéndez Pidal, s/n. 14004, Córdoba, Spain, e-mail: fperez@sofia.hrs.sas.cica.es

Abbreviations: $\mathrm{CHO}$, carbohydrate; CT, total cholesterol; HDL-C, HDL-cholesterol; LDL-C, LDL-cholesterol; MONO, monounsaturated fat; SSPG, steady state plasma glucose; SSPI, steady state plasma insulin; USDA, United States Department of Agriculture nary heart disease (CHD). In 1988 "Syndrome X" was [1] first described as a cluster of pathophysiologic phenomena including insulin resistance, glucose intolerance, dyslipidemia, and abdominal obesity.

The relation between diet and chronic disease is well established, although there is debate over the details of this relation. In general, high intakes of dietary fat have been associated with obesity and its comorbid conditions, including heart disease and diabetes [2]. All these factors are related to the globalization of the "Western" lifestyle and dietary habits. Insulin resistance usually precedes the diagnosis of Type II (non-insulin-dependent) diabetes mellitus by 
decades and in most cases, the clinical expression of the disease could be prevented by dietary and lifestyle modification. A diet high in fiber, low in saturated fatty acids (SFA) and low in simple carbohydrates $(\mathrm{CHO})$ is accepted as beneficial for patients with Type II diabetes mellitus and CHD. However, there is still some debate over whether the best source of replacement calories for SFA fat comes from monounsaturated (MONO) fats or from complex CHO. In a recent meta-analysis of ten randomized-crossover trials using isocaloric diets, it was concluded that high-MONO fat diets might be more advantageous than high $\mathrm{CHO}$-diets for improving lipoprotein and glycaemic profiles in patients with Type II diabetes [3]. Furthermore, the high intakes of oleic acid in the Mediterranean region coincide with low rates of total mortality and CHD [4]. Insulin resistance and its clinical expression as Type II diabetes mellitus is probably influenced and determined by diet in the early stages of growth and development. However, few studies have addressed the effect of both high-CHO and high-MONO fat diets on glucose metabolism in non-diabetic subjects using well-controlled crossover randomized dietary intervention protocols. We conducted this study to investigate the effects of the isocaloric substitution of $\mathrm{CHO}$ and monounsaturated fatty acids (MUFA) for SFA fat, on in vivo and in vitro glucose metabolism, using the insulin suppression test and glucose disposal in peripheral monocytes obtained after each dietary period.

\section{Subjects and methods}

Subjects and diets. Fifty-nine healthy normolipemic (total plasma cholesterol values lower than $5.2 \mathrm{mmol} / \mathrm{l})$ subjects $(30 \mathrm{men}$ and 29 women), attending the University of Cordoba volunteered to participate in the study. All underwent a comprehensive medical history, physical examination and clinical chemistry analyses before enrollment. Subjects were younger than 30 years of age (mean age $23.1 \pm 1.8$ ), with no evidence of any chronic illness (such as hepatic, renal, thyroid, or cardiac dysfunction), or unusually high values of physical activity. Mean initial BMI was $22.87 \pm 2.45$ and remained constant throughout the experimental period. Mean basal weight was $67.01 \pm 11.5$. This weight was not modified at the end of each dietary period $(66.35 \pm 11.6 ; 66.24 \pm 11.0$ and $66.34 \pm 11.3$, in saturated diet, $\mathrm{CHO}$-diet and Mediterranean diet, respectively).

Dietary information, including alcohol consumption, was collected over seven consecutive days. Individual energy requirements were calculated by taking into consideration each participant's weight and physical activity. The participants were encouraged to maintain their regular physical activity and lifestyle and were asked to record any event that could affect the outcome of the study in a diary, such as stress, change in smoking habits and alcohol consumption or foods not included in the experimental design.

The study design included an initial 28-day period during which all the subjects consumed a saturated fat (SFA) enriched diet with $15 \%$ of energy as protein, $47 \%$ as carbohydrate
(CHO), and $38 \%$ as fat [20\% SFA, $12 \%$ monounsaturated fatty acids (MUFA) and $6 \%$ polyunsaturated fatty acids (PUFA)]. All participants were then randomized in a crossover design and exposed to two new dietary periods: a low fat, high carbohydrates diet (CHO-diet), and a high-MUFA diet, with a typical "Mediterranean diet" enriched with olive oil. The two groups of subjects were assigned to one of two dietary regimes for 28 days each. Group 1 (30 subjects) was placed on a Mediterranean diet followed by a $\mathrm{CHO}$-diet. For group 2 (29 subjects) the order was reversed. Assignment of volunteers to the sequence of diets was carried out at random. The CHOdiet [5] contained $15 \%$ of energy as protein, $57 \%$ as $\mathrm{CHO}$, and $28 \%$ as fat ( $<10 \%$ SFA, $12 \%$ MUFA, and $6 \%$ PUFA). The MUFA-enriched diet contained $15 \%$ of energy as protein, $47 \%$ as $\mathrm{CHO}$, and $38 \%$ as fat $(<10 \%$ SFA, $22 \%$ MUFA, and $6 \%$ PUFA). Olive oil provided $75 \%$ of total MUFA consumed during this last dietary period. All diets lasted for 28 days. Dietary cholesterol remained constant in our experimental design and the mean cholesterol intake was $115 \mathrm{mg} /$ $1000 \mathrm{kcal}$ during the three periods. The Human Investigation Review Committee approved this study at the Reina Sofia University Hospital. Informed consent was obtained from all participants.

The composition of the experimental diets was calculated using the United States Department of Agriculture (USDA) food tables or the Spanish food composition tables for local foodstuffs. Fourteen menus were prepared with regular solid foods and rotated during the experimental period. We used virgin olive oil for cooking and as a salad dressing during the Mediterranean diet. Palm oil and butter were used for the high-SFA diet. During the CHO-diet period, biscuits, bread and jam replaced some olive oil or palm oil. Lunch and dinner were consumed in the hospital dining room, whereas breakfast and an afternoon coffee break were taken in the medical school cafeteria. A dietitian supervised all meals. Duplicate samples from each menu were collected, homogenized, and stored at $-80^{\circ} \mathrm{C}$. Protein, fat and $\mathrm{CHO}$ content of the diet were analysed using standard methods [6]. Dietary compliance was also evaluated by examining the food diaries and by analysing the fatty acid content of the cholesterol ester fraction in LDL [7].

Blood sampling and biochemical determinations. Venous blood for insulin, glucose, lipid and lipoprotein analysis were collected in EDTA containing tubes from the subjects after a 12-h overnight fast at the end of each dietary period. Each analysis was done three times. Cholesterol (TC) and triglycerides were assayed by enzymatic procedures $[8,9]$. HDL-C was measured by analysing the supernatant obtained after precipitation of a plasma aliquot with dextran sulfate- $\mathrm{Mg}^{2+}$ [10]. LDL-C values were calculated from the total cholesterol, triglycerides, and HDL-C values using the Friedewald formula [11]. Unesterified free fatty acid values were analysed by an enzymatic colorimetric assay (Boehringer Mannheim, Mannheim, Gemanny) [12]. To reduce interassay variation, plasma for biochemical determinations was stored at $-80^{\circ} \mathrm{C}$ and analysed in duplicate at the end of the study.

Glucose suppression test. At the end of each dietary period all subjects underwent a modified insulin suppression test [13, 14]. The study began at 0800 hours, after twelve hours of fasting. A continuous infusion of somatostatin $(214 \mathrm{nmol} / \mathrm{h})$, insulin $\left(180 \mathrm{pmol} \cdot \mathrm{m}^{-2} \cdot \mathrm{min}^{-1}\right)$, and glucose $\left(13.2 \mathrm{mmol} \cdot \mathrm{m}^{-2}\right.$. $\mathrm{min}^{-1}$ ) were infused in the same vein. Somatostatin was used to inhibit endogenous insulin secretion. Blood was sampled every $30 \mathrm{~min}$ for the first $2.5 \mathrm{~h}$, by which time steady state plasma glucose (SSPG) and steady-state plasma insulin (SSPI) values 
were achieved. Blood was then sampled at 10 -minute intervals for the last $30 \mathrm{~min}$ (at 150, 160, 170 and $180 \mathrm{~min}$ ) to measure plasma glucose and insulin concentrations. These four values determined the SSPG and SSPI concentrations. Since SSPI values were similar in all subjects, SSPG values provided a measure of the ability of insulin to promote disposal of infused glucose. Subjects with high SSPG are relatively more insulin resistant than subjects with lower SSPG.

Separation of circulating monocytes. Circulating mononuclear cells were separated by the Ficoll-Hypaque procedure. Mononuclear cells collected from the interface were washed twice by centrifugation at $230 \cdot \mathrm{g}$ for $10 \mathrm{~min}$ to remove the remaining Ficoll-Hypaque and in $6 \mathrm{ml}$ of HEPES-buffered RPMI culture medium by centrifugation at $100 \cdot \mathrm{g}$ for $5 \mathrm{~min}$ to remove contaminating platelets and to obtain the mononuclear cell population. Monocytes were separated by adherence to 24-well plates by incubation with HEPES-RPMI medium containing $10 \%$ bovine calf serum at $370 \mathrm{C}$ for $4 \mathrm{~h}$. Monocytes adhered to the bottom of the wells, whereas lymphocytes remained in the supernatant. The cells were maintained at room temperature for less than $3 \mathrm{~h}$ until assayed for 2-deoxyglucose (2-DG) uptake. $\left({ }^{3} \mathrm{H}\right) 2-\mathrm{DG}$ was obtained from Amersham Life Science (Piscataway, N.J., USA) and unlabelled 2-DG from Sigma (St. Louis, Mo., USA).

Glucose uptake in monocytes. Glucose uptake in monocytes was carried out as described previously [15]. In summary, monocytes were resuspended in glucose-free HEPES-buffered saline solution and incubated in the presence of $75 \mu \mathrm{mol} / \mathrm{l}$ $\left({ }^{3} \mathrm{H}\right) 2-\mathrm{DG}$ (sp. act $156 \mathrm{mCi} / \mathrm{mmol}$ ) at $37{ }^{\circ} \mathrm{C}$ with mild agitation. Uptake was stopped by adding $50^{\circ} \mu l$ glucose-free HEPES-buffered solution containing $10^{\circ} \mu \mathrm{mol} / \mathrm{l}$ cytochalasin B (Sigma). The cells were quickly separated from the radioactive solution and lysed by adding $400^{\circ} \mu \mathrm{l} 0.05 \mathrm{~N} \mathrm{NaOH}$, and cell-associated radioactivity was analysed by scintillation counting. Parallel determination of control hexose uptake were done in the presence of $25 \mu \mathrm{mol} / \mathrm{l}$ cytochalasin B and the radioactivity associated with these cell pellets was subtracted from all the results. Each measurement was done at least twice. 2-DG uptake was analysed both in the absence (basal glucose uptake) and presence (insulin-stimulated glucose uptake) of insulin by incubating the cells for $1 \mathrm{~h}$ respectively, without or with $10 \mathrm{nmol} / \mathrm{l}$ insulin, at $370{ }^{\circ} \mathrm{C}$ in HEPES-buffered RPMI medium.

Statistical analyses. Statistical analyses were carried out using the SPSS statistical package. ANOVA for repeated measures was used to analyse the differences in plasma lipid, glucose, SSPG values and basal glucose and insulin-stimulated glucose uptake between dietary phases. When statistically significant effects were observed, Tukey's post-hoc test was used to identify differences between groups. Correlation analysis was done with Pearson's correlation coefficient. A $p$ value of less than 0.05 was considered statistically significant. All data are given in the text and tables as means \pm SD.

\section{Results}

Dietary composition was analysed in duplicate meal portions. Results are shown in Table 1 . The results were in close agreement with values obtained from the food composition tables. Fatty acid composition was analysed during each dietary period on the cholesterol ester fraction of plasma LDL (Table 2). En-
Table 1. Mean daily intake during each experimental diet period (means $\pm \mathrm{SD}$ )

\begin{tabular}{|c|c|c|c|}
\hline & $\begin{array}{l}\text { High SFA } \\
\text { diet }\end{array}$ & $\mathrm{CHO}$ diet & $\begin{array}{l}\text { Mediter- } \\
\text { ranean } \\
\text { diet }\end{array}$ \\
\hline \multicolumn{4}{|c|}{ Protein (\% of energy intake) } \\
\hline Calculated & 15 & 15 & 15 \\
\hline Analysed & $18.1 \pm 2.5$ & $17.6 \pm 1.5$ & $17.5 \pm 2.0$ \\
\hline \multicolumn{4}{|c|}{ Fat (\% of energy intake) } \\
\hline \multicolumn{4}{|c|}{ Saturated } \\
\hline Calculated & 20 & 10 & 10 \\
\hline Analysed & $22.6 \pm 4.1$ & $9.2 \pm 3.5$ & $9.2 \pm 4.2$ \\
\hline \multicolumn{4}{|c|}{ Monounsaturated } \\
\hline Calculated & 12 & 12 & 22 \\
\hline Analysed & $10.1 \pm 2.9$ & $13.5 \pm 1.2$ & $24.4 \pm 2.2$ \\
\hline \multicolumn{4}{|c|}{ Polyunsaturated } \\
\hline Calculated & 6 & 6 & 6 \\
\hline Analysed & $5 \pm 1.5$ & $5.2 \pm 2.0$ & $4.8 \pm 1.1$ \\
\hline \multicolumn{4}{|c|}{$\begin{array}{l}\text { Carbohydrates (\% of } \\
\text { energy intake) }\end{array}$} \\
\hline Calculated & 47 & 57 & 47 \\
\hline Analysed & $44.2 \pm 8.3$ & $54.5 \pm 8.6$ & $44.1 \pm 7.8$ \\
\hline \multicolumn{4}{|c|}{ Cholesterol (mg/d) } \\
\hline Calculated & 115 & 115 & 115 \\
\hline Analysed & $112 \pm 39$ & $113 \pm 48$ & $117 \pm 42$ \\
\hline \multicolumn{4}{|l|}{ Energy (MJ) } \\
\hline Calculated & 10.2 & 10.2 & 10.2 \\
\hline Analysed & $10.8 \pm 1.1$ & $10.6 \pm 1.0$ & $10.8 \pm 1.5$ \\
\hline \multicolumn{4}{|c|}{ Dietary fiber $(\mathrm{g} / \mathrm{d})$} \\
\hline Calculated & 30 & 30 & 30 \\
\hline Analysed & $25.9 \pm 7.0$ & $26.1 \pm 6.1$ & $24.9 \pm 8.2$ \\
\hline
\end{tabular}

SFA diet, saturated fat-enriched diet; $\mathrm{CHO}$ diet, low-fat, highcarbohydrate diet

Table 2. Fatty acid composition means \pm SD of LDL cholesterol esters during each diet phase

\begin{tabular}{lccc}
\hline Fatty acid & High SFA diet & CHO diet & $\begin{array}{l}\text { Mediterranean } \\
\text { diet }\end{array}$ \\
\hline $16: 0$ & $27.2 \pm 1.4^{\mathrm{ab}}$ & $18.9 \pm 3.9$ & $15.1 \pm 0.4$ \\
$16: 1$ & $2.2 \pm 0.9$ & $2.3 \pm 0.3$ & $1.9 \pm 0.2$ \\
$18: 0$ & $2.8 \pm 1.1$ & $2.4 \pm 0.8$ & $2.5 \pm 0.4$ \\
$18: 1$ & $45.5 \pm 4.4$ & $38.5 \pm 9$ & $49.7 \pm 4.7^{\mathrm{c}}$ \\
$18: 2$ & $20.2 \pm 3.6^{\mathrm{c}}$ & $33.6 \pm 16$ & $26.4 \pm 4.8$ \\
\hline
\end{tabular}

${ }^{a}$ Significantly different from CHO diet $(p<0.004)$.

${ }^{\mathrm{b}}$ Significantly different from Mediterranean $\operatorname{diet}(p<0.0004)$.

'Significantly different from CHO diet $(p<0.05)$

SFA diet, saturated fat enriched diet; CHO diet, low-fat, highcarbohydrate diet

richment in palmitic acid was observed during the SFA diet and in oleic acid during the Mediterranean diet, suggesting good adherence to the dietary protocol. TC, LDL-Cholesterol (LDL-C) and HDLCholesterol (HDL-C) were significantly reduced $(p<0.001)$ following the consumption of the $\mathrm{CHO}$ and Mediterranean diets as compared with the SFAenriched diet (Table 3). There were no significant differences between the $\mathrm{CHO}$ and the Mediterranean diet for any of the lipid parameters examined. Fasting glucose plasma values did not show significant differ- 
Table 3. Mean of plasma lipids, lipoprotein values and other metabolic parameters $( \pm \mathrm{SD})$ after each of the dietary periods

\begin{tabular}{|c|c|c|c|}
\hline & $\begin{array}{l}\text { High SFA } \\
\text { diet }\end{array}$ & $\mathrm{CHO}$ diet & $\begin{array}{l}\text { Mediterra- } \\
\text { nean diet }\end{array}$ \\
\hline Triglycerides (mmol/l) & $0.77 \pm 0.3$ & $0.78 \pm 0.2$ & $0.79 \pm 0.3$ \\
\hline Total cholesterol (mmol/l) & $4.27 \pm 0.6^{\mathrm{ab}}$ & $3.67 \pm 0.7$ & $3.74 \pm 0.7$ \\
\hline HDL cholesterol (mmol/l) & $1.12 \pm 0.3^{\mathrm{ab}}$ & $0.99 \pm 0.2$ & $1.03 \pm 0.2$ \\
\hline LDL cholesterol (mmol/l) & $2.80 \pm 0.5^{\mathrm{ab}}$ & $2.32 \pm 0.5$ & $2.34 \pm 0.6$ \\
\hline Fasting glucose (mmol/l) & $4.89 \pm 0.3$ & $4.87 \pm 0.4$ & $4.79 \pm 0.4$ \\
\hline Fasting insulin (UI/l) & $32.3 \pm 9.3^{\mathrm{ab}}$ & $13.8 \pm 5.2$ & $14.7 \pm 8.5$ \\
\hline $\begin{array}{l}\text { Fasting free fatty acids } \\
(\mathrm{mmol} / \mathrm{l})\end{array}$ & $0.52 \pm 0.3^{\mathrm{ab}}$ & $0.37 \pm 0.2$ & $0.37 \pm 0.2$ \\
\hline $\begin{array}{l}\text { Mean glucose in SSPG } \\
(\mathrm{mmol} / \mathrm{l})\end{array}$ & $8.06 \pm 4.09^{\mathrm{ab}}$ & $6.61 \pm 3.09$ & $6.25 \pm 3.08$ \\
\hline $\begin{array}{l}\text { In vitro basal glucose up- } \\
\text { take }\left(\text { pmol } \cdot \min \cdot 5 \cdot 10^{5}\right)\end{array}$ & $10.6 \pm 1.48^{\mathrm{ab}}$ & $27.4 \pm 2.37$ & $24.7 \pm 2.51$ \\
\hline $\begin{array}{l}\text { In vitro insulin-stimulated } \\
\text { glucose uptake (pmol } \\
\left.\min ^{-1} \cdot 5 \cdot 10^{5}\right)\end{array}$ & $16 \pm 2.24^{\mathrm{ab}}$ & $35.8 \pm 2.74$ & $36.28 \pm 3.46$ \\
\hline
\end{tabular}

${ }^{\mathrm{a}} p<0.001$ with $\mathrm{CHO}$ diet.

${ }^{\mathrm{b}} p<0.001$ with Mediterranean diet

SFA diet, saturated fat enriched diet; CHO diet, low-fat, highcarbohydrate diet

ences between the diet periods. Fasting plasma values of insulin and non-esterified fatty acids (NEFA) were significantly higher during the high-SFA diet than during the $\mathrm{CHO}$ and Mediterranean diets (Table 3). Insulin values during the SSPI period (mean \pm SD in $\min 150,160,170$ and 180 of insulin suppression test) were similar after the three diets $(100.1 \pm 30.5$, $100.2 \pm 30.5, \quad 90.9 \pm 10.7, \quad 100.1 \pm 10.3 \mathrm{pmol} / 1$ for high-SFA; $\quad 90.9 \pm 30.2, \quad 100.4 \pm 20.8, \quad 100.2 \pm 20.6$, $100 \pm 20.6 \mathrm{pmol} / \mathrm{l}$, for MUFA diet and $90.3 \pm 20.2$, $90.9 \pm 20.4,100.1 \pm 20.7,90.9 \pm 20.6 \mathrm{pmol} / \mathrm{l}$ for $\mathrm{CHO}-$ diet). However, SSPG values were substantially lower during both the Mediterranean and $\mathrm{CHO}$-diets compared with the high-SFA diet $(p=0.007)$; indicating an improvement in insulin sensitivity (Table 3 ). No differences were found between the $\mathrm{CHO}$ or the Mediterranean diet or between men and women (data not shown). The mean glucose values of the SSPG period changed in parallel with fasting NEFA plasma values (Table 3), indicating the characteristic relation between insulin sensitivity and NEFA plasma values. Furthermore, the NEFA plasma values were correlated positively with SSPG $(r=0.45$; $p<0.0001$; Fig. 1$)$. The basal and insulin-stimulated glucose uptake of 2-deoxiglucose in peripheral monocytes, obtained during each dietary period, increased after the Mediterranean $(p<0.001)$ and $\mathrm{CHO}$ diets $(p<0.001)$ compared with the high-SFA diet, parallel to the changes in in vivo glucose disposal (Table 3 ). Additionally, there was a significantly inverse correlation between the mean glucose of the SSPG period and logarithmic values of basal and insulin stimulated glucose uptake in monocytes (basal uptake $r=-0.34$;

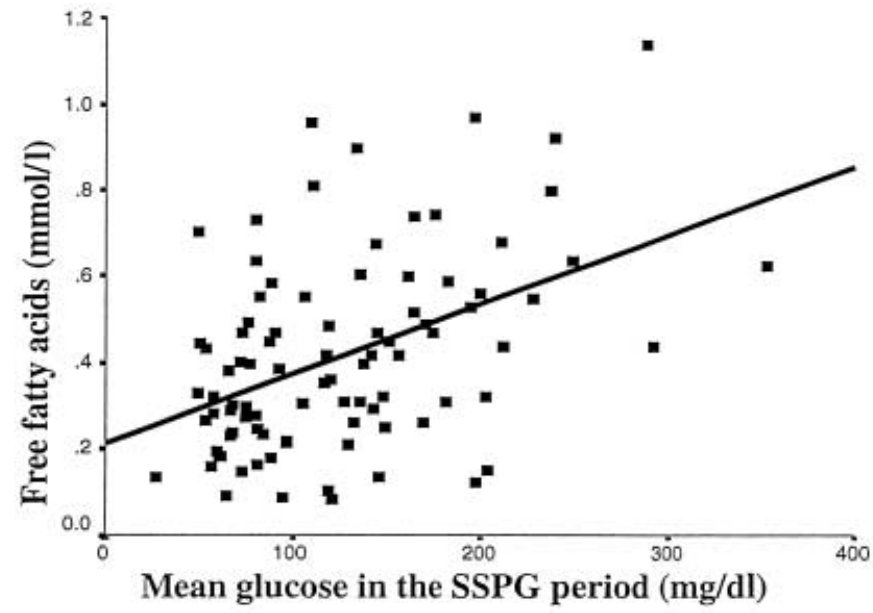

Fig. 1. Relation between steady-state plasma glucose (SSPG) and fasting free fatty acids plasma values. $r=0.45, p=0.0001$

$p=0.003$ and insulin stimulated uptake $r=-0.32$; $p=0.006)$.

\section{Discussion}

Our data show that the isocaloric substitution of CHO or MUFA in an enriched Mediterranean diet for SFA in a young healthy normolipemic population, improves in vivo insulin sensitivity found with the insulin suppression test. We also found an increase in in vitro glucose uptake by monocytes obtained during a Mediterranean diet and the $\mathrm{CHO}$-diet. These findings were positively correlated with in vivo glucose disposal. These data have been obtained in free living conditions using natural food, thus increasing the generalization of our findings.

Reduction in SFA fat intake improves insulin sensitivity in patients with Type II diabetes $[16,17]$ and agrees with our results in healthy subjects. However, debate continues as to whether dietary SFA should be replaced with $\mathrm{CHO}$ or MUFA. Our data indicate that $\mathrm{CHO}$ and Mediterranean diets are equally effective at promoting in vivo disposal of glucose, since both diets showed a similar decrease in SSPG.

It is important to stress that the three diets in our study contained the same fiber content. Although studies exist which demonstrate that an increase in carbohydrates, without an increase in fiber, does not improve glucose metabolism [18] a recent study showed that diets with different carbohydrate content but with an equal content of fiber, improve glucose metabolism [19]. The putative basic defect in Type II diabetes and in metabolic syndrome is the resistance to insulin-mediated glucose disposal, which favors fasting and postprandial hyperinsulinaemia. Insulin response to nutrient intake increases in relation to the amount of dietary $\mathrm{CHO}$ [20]. If CHO intake is increased, an additional amount of insulin 
must be secreted in order to maintain glucose homeostasis. When insulin resistance progresses, the difficulty of the pancreas to produce additional insulin will impair glucose metabolism, as has been shown in Type II diabetic patients. However, if the pancreas can respond with sufficient hormone secretion, as in our healthy subjects, plasma glucose could be maintained within normal values and fasting insulinaemia and peripheral sensitivity should remain within normal limits [21]. It has been suggested [3] that improvement in the glycaemic profile of diabetic patients with a high-MONO diet, compared with a high-CHO diet, might not be related to changes in insulin sensitivity but rather to a reduction in the carbohydrate load, which Type II diabetic patients might not be able to readily handle. This could explain the discrepancies found between our data in healthy subjects with adequate insulin secretion and data from studies which include Type II diabetic patients.

Of interest, we found that fasting NEFA plasma values decreased after isocaloric replacement of MUFA and CHO for SFA. Furthermore, the mean value of SSPG as an index of glucose uptake, correlated positively with NEFA plasma values. Non-esterified fatty acid plasma values are typically increased in insulin resistant states. Several decades ago it was proposed [22] that high values of fatty acids could play a causal role in the development of insulin resistance by competing with glucose for oxidation $[23,24]$.

The in vitro basal and insulin-stimulated glucose uptake increased during the isocaloric substitution of MUFA and CHO for SFA fat, thus confirming the findings observed for the in vivo studies. Skeletal muscle is the most important site of peripheral insulin resistance [25] but this tissue is relatively inaccessible for routine evaluation of insulin action in humans. Mononuclear cells are not a typical insulin target tissue but they do have the advantage of being the only easily accessible human cell system available to study insulin action at the cellular level [26]. 2-DG uptake represents hexose transport and glucose uptake in isolated monocytes has been previously shown to respond to insulin in a dose-dependent manner [15]. The current in vitro model has been previously shown to have an abnormally low basal and insulin-stimulated glucose uptake in cells from Type II diabetic patients. These cells have glucose metabolism-related enzyme activity comparable to the activity in typical insulin target tissues [27]. Moreover, they exhibit the insulin activation of receptor kinase, with impairment of this activation in intact cells from patients with Type II diabetic patients [26]. This evidence suggests that peripheral monocytes could serve as an indirect model system to assess impaired peripheral insulin action in Type II diabetes and to investigate in vitro insulin sensitivity [28]. The relation between in vivo and in vitro glucose disposal was shown by the fact that in vitro 2-DG uptake correlated negatively with mean glucose in the last half-hour of the insulin suppression test.

In summary, our findings suggest that both the Mediterranean diet and the low-fat, high-CHO diet improve insulin sensitivity in vivo and in vitro, in healthy subjects and could help prevent Type II diabetes mellitus.

Acknowledgements. This work was supported by research grants from the CAICYT (96/0060, to F. Pérez-Jiménez), the Spanish Ministry of Health (FIS 93/0746, 94/1547, 95/1144, 96/ 1540, 98/1531 to J. López-Miranda), Health Department, Andaluz Health Service (PAI 96-54, 97, 98, 99) (to J. LópezMiranda), Agriculture Department from the Government of Andalucía (to F. Pérez-Jiménez), Patrimonio Comunal Olivarero and The National Institutes of Health, Bethesda, Md., USA (HL 54776, to J.M. Ordovás). We thank all the subjects who participated in the study for their cooperation and enthusiasm.

\section{References}

1. Reaven G (1988) The role of insulin resitance in human disease. Diabetes 37: 1595-1607

2. Lovejoy JC (1999) Dietary fatty acids and insulin resistance. Curr Atheroscler Rep 1: 215-220

3. Garg A (1998) High-monounsaturated-fat diets for patients with diabetes mellitus: a meta-analysis. Am J Clin Nutr 67[Suppl]: 577S-582S

4. Keys A (1970) Coronary heart disease in seven countries. Circulation 41: 1-211

5. National Cholesterol Education Program (1994) Second Report of the Expert Panel on detection, evaluation, and treatment of high blood cholesterol in adults (Adult Treatment Panel II). Circulation 89: 1330-1445

6. Association of Official Analytical Chemists (1990) Official methods of analysis, 15th edn (modified). Association of Official Analytical Chemists, Arlington

7. Ruiz-Gutierrez V, Prada JL, Pérez Jiménez F (1993) Determination of fatty acid and triacylglycerol composition of human very low density lipoproteins. J Chromatogr 662: 117-134

8. Allain CC, Poon LS, Chang CSG, Richmond W, Fu PC (1974) Enzymatic determination of total serum cholesterol. Clin Chem 20: 470-475

9. Bucolo G, David H (1973) Quantitative determination of serum triglycerides by use of enzymes. Clin Chem 19: 476-482

10. Warnick GR, Benderson J, Alberts JJ (1982) Dextran sulfate- $\mathrm{Mg}+$ precipitation procedure for quantitation of high density lipoprotein cholesterol 28: 1379-1388

11. Friedewald WT, Levy RI, Fredrickson DS (1972) Estimation of the concentration of low density lipoprotein cholesterol in plasma without use of preparative ultracentrifuge. Clin Chem 18: 499-502

12. Shimizu S, Inoue K, Tani Y, Yamada H (1979) Enzymatic microdetermination of serum free fatty acids. Anal Biochem 98: 341-345

13. Harano Y, Ohgaku S, Hidaka H et al. (1977) Glucose, insulin and somatostatin infusion for the determination of insulin sensitivity. J Clin Endocrinol Metab 45: 1124-1127

14. Laws A, Jeppesen JL, Maheux PC, Schaal P, Chen YD, Reaven GM (1994) Resistance to insulin-stimulated glu- 
cose uptake and dyslipidemia in Asian Indian. Arterioscler Thromb 14: 917-922

15. Daneman D, Zinman B, Elliot ME, Bilan P, Klip A (1992) Insulin-stimulated glucose transport in circulating mononuclear cells from nondiabetic and IDDM subjects. Diabetes 41: 227-234

16. Purnell JQ, Brunzell JD (1997) The central role of dietary fat, non carbohydrate, in the insulin resistance syndrome. Curr Opin Lipidol 8: 17-22

17. Vessby B, Uusitupa M, Hermensen K et al. (2001) Substituting dietary saturated for monounsaturated fat impairs insulin sensitivity in healthy men and women: The KANWU study. Diabetologia 44: 312-319

18. Riccardi G, Rivellese AA (1991) Effects of dietary fiber and carbohydrate on glucose and lipoprotein metabolism in diabetic patients. Diabetes Care 14: 1115-1125

19. Bisschop PH, de Metz J, Ackermans MT et al. (2001) Dietary fat content alters insulin-mediated glucose metabolism in healthy men. Am J Clin Nutr 73: 554-559

20. Hollenbeck CB, Chen N, Chen Y-DI, Reaven GM (1984) Relationship between the plasma insulin response to oral glucose and insulin-stimulator glucose utilization in normal subject. Diabetes 33: 460-463

21. Garg A, Bantle JP, Henry RR et al. (1994) Effect of varying carbohydrate content of diet in patients with non-insulin dependent diabetes mellitus. JAMA 271: 1421-1428

22. Randle J, Garland PB, Hales CN, Newsholme EA (1963) The glucose-fatty acid cycle, its role in insulin sensitivity and the metabolic disturbances of diabetes mellitus. Lancet 785-789

23. Thorburn AW, Storlein LH, Jenkins AB, Khouri S, Kraegen EW (1998) Fructose-induced in vivo insulin sensitivity and the metabolic disturbances of diabetes mellitus. Metabolism 47: 1520-1524

24. Storlein LH, Jenkins AB, Chisholm DJ, Pascoe WS, Khauri S, Kraegen EW (1991) Incluence of dietary fat composition on the development of insulin resitance in rats: Relationship to muscle triglyceride and w-3 fatty acids in muscle phospholipid. Diabetes 40: 280-289

25. Perseghin G, Price TB, Petersen KF et al. (1996) Increased glucose transport-phosphorylation and muscle glycogen synthesis after exercise training in insulin resistant subjects. N Engl J Med 335: 1357-1362

26. Klein HH, Kowalewski B, Drenckhan M, Neugebauer S, Matthaei S, Kotzke G (1993) A microtiter well assay system to measure insulin activation of insulin receptor kinase in intact human mononuclear cells. Diabetes 42: 883-890

27. Mogghetti P, Bonora E, Cigolini M et al. (1990) Enzymatic activities related to intermediary metabolism of glucose in circulating mononuclear cells from obese humans: relationship to enzyme activity in adipose tissue. Enzyme 43: 26-32

28. Olefsky JM, Reaven GM (1977) Insulin binding in diabetes: relationship with plasma insulin levels and insulin sensitivity. Diabetes 26: 680-688 